\title{
Influence of the structural and surface properties on photocatalytic activity of $\mathrm{TiO}_{2}: \mathrm{Nd}$ thin films
}

\author{
Damian Wojcieszak ${ }^{\mathbf{1}}$,Michał Mazur ${ }^{*}$, Danuta Kaczmarek ${ }^{\mathbf{1}}$, Jerzy Morgiel $^{\mathbf{2}}$, Agata Poniedziałek ${ }^{\mathbf{1}}$, \\ Jarosław Domaradzki ${ }^{1}$, Aleksandra Czeczot $^{1}$
}

${ }^{1}$ Wroclaw University of Technology, Faculty of Microsystem Electronics and Photonics, Janiszewskiego 11/17, 50-372

Wroclaw, Poland

${ }^{2}$ Polish Academy of Sciences, Institute of Metallurgy and Materials Science, Reymonta 25, 30-059 Cracov, Poland

*Corresponding author: e-mail: michal.mazur@pwredu.pl

\begin{abstract}
Titanium dioxide thin films doped with the same amount of neodymium were prepared using two different magnetron sputtering methods. Thin films of anatase structure were deposited with the aid of Low Pressure Hot Target Magnetron Sputtering, while rutile coatings were manufactured using High Energy Reactive Magnetron Sputtering process. The thin films composition was determined by energy dispersive spectroscopy and the amount of the dopant was equal to 1 at. \%. Structural properties were evaluated using transmission electron microscopy and revealed that anatase films had fibrous structure, while rutile had densely packed columnar structure. Atomic force microscopy investigations showed that the surface of both films was homogenous and consisted of nanocrystalline grains. Photocatalytic activity was assessed based on the phenol decomposition. Results showed that both thin films were photocatalytically active, however coating with anatase phase decomposed higher amount of phenol. The transparency of both thin films was high and equal to ca. $80 \%$ in the visible wavelength range. The photoluminescence intensity was much higher in case of the coating with rutile structure.
\end{abstract}

Keywords: $\mathrm{TiO}_{2}$, neodymium, thin films, magnetron sputtering, photocatalysis, phenol decomposition.

\section{INTRODUCTION}

One of the materials that has lately attracted much attention is titanium dioxide $\left(\mathrm{TiO}_{2}\right)^{\mathbf{1}-4}$. Such interest is related to the unique properties of this material, e.g. nontoxicity, thermal, mechanical and chemical stability, transparency for the light in the wide spectral range, high dielectric constant and photocatalytic activity ${ }^{5-9}$. According to the application it is desired to obtain titanium dioxide with different crystal structure - anatase, rutile as well as a mixture of these two phases. Thin films with the rutile structure can be used as films with high refractive index in case of antireflective coatings, optical filters, protective coatings for solar cells or touch panels ${ }^{10-13}$. In turn, $\mathrm{TiO}_{2}$ thin films with anatase structure are widely applied as coatings with hydrophilic and self-cleaning properties due to their high photocatalytic properties ${ }^{14-16}$. Titania is well known and widely used effective photocatalyst for the photodegradation of organic pollutants in water and air ${ }^{17}$. The efficiency of the photocatalytic process of $\mathrm{TiO}_{2}$ in aqueous solution depends on the electron-hole pairs generated under the light illumination, separation and transfer of electrons and holes to harmful compounds adsorbed on the catalyst surface $^{18}$. The photogenerated holes in the titania are highly oxidizing and play key role in the photocatalysis process. However, recombination of electron/hole pairs significantly decreases its efficiency ${ }^{19}$. Therefore, various efforts are made to avoid the recombination process. Doping the titania catalyst with proper metal ions could be advantageous and increase its photocatalytic properties by introducing or increasing the number of trapping sites. Trapping electrons and holes can lead to increased lifetimes and therefore the probability of reaching the surface without further recombination, allowing them to take part in the photocatalysis reaction ${ }^{20}$.

Lanthanides as dopants for thin films based on $\mathrm{TiO}_{2}$ can modify their surface properties that favourably influ- ence on e.g. increase of photocatalytic activity ${ }^{21-23}$. Most of the rare earths (Ce, Sm, Er, La, Eu, Pr, Gd and Nd) have been found to improve photocatalytic properties of $\mathrm{TiO}_{2}$. Among samples doped with $\mathrm{Sm}, \mathrm{Ce}, \mathrm{Er}, \mathrm{Pr}, \mathrm{La}$ the Gd- and Nd-doped $\mathrm{TiO}_{2}$ showed highest photocatalytic activity $^{18}$. Depending on the experimental setup, time of the decomposition and decomposed material the photocatalytic activity of pure titania in the form of nanopowders reported in the literature may be high $^{17,18,23,24}$. However, the photocatalytic activity of $\mathrm{TiO}_{2}$ may be further enhanced by doping with e.g. neodymium. Jiang et al. ${ }^{25}$ reported that only precisely selected amount of $\mathrm{Nd}$ dopant can significantly increase the photocatalytic properties of $\mathrm{TiO}_{2}$. For example, Khalid et al. ${ }^{26}$ stated that the optimum value of the neodymium dopant incorporated into titania nanoparticles is ca. 1 at. $\%$ and then the efficiency of the photocatalytic reaction is enhanced by $20 \%$. Also Bokare et al. ${ }^{27}$ showed that incorporation of 1 at. $\%$ of neodymium increased the decomposition efficiency of $30 \%$ as-compared to undoped $\mathrm{TiO}_{2}$. The effectiveness of the dopant is related to its ionic radius and oxygen affinity of the dopant ion. Therefore, the large $\mathrm{Nd}^{3+}$ ion can produce a localized charge perturbation when it is present substitutionally in titania and, in such way, enhances its photocatalytic activity ${ }^{28}$.

Up to date there are a lot of reports regarding the preparation of the oxide composites based on titanium and neodymium by various techniques. Most of them concern preparation of nanopowders and the commonly used sol-gel method ${ }^{27,29}$. However, the reports about preparation of $\mathrm{TiO}_{2}: \mathrm{Nd}$ thin film coatings are rare e.g. ${ }^{30,31}$ and among others one can also distinguish such fabrication methods as e.g.: pyrolysis $^{32}$, spin-coating ${ }^{33}$ or laser ablation ${ }^{34}$. Also magnetron sputtering is a popular method for the deposition of thin film coatings in various fields of industry, e.g. optical coatings or thin-film gas sensors ${ }^{35,36}$. One advantage of this technique includes the 
possibility of the deposition of dielectric, semiconducting or conducting thin films on large area surfaces ${ }^{37}$.

In the literature the vast information about photocatalytic properties of titania in the form of nanopowders can be found, however there is a lack of data concerning photocatalytic activity of thin films based on $\mathrm{TiO}_{2}$, especially doped with neodymium ${ }^{21,23}$. Therefore, in this study, as-prepared $\mathrm{Nd}$-doped titanium dioxide thin films with various crystal phases were prepared and used for the photocatalytic degradation of the phenol. Additionally, their structure, surface and optical properties were also determined.

\section{EXPERIMENTAL DETAILS}

To obtain various crystal phases, the titanium dioxide thin films doped with 1.0 at. $\%$ of neodymium were prepared by two different magnetron sputtering processes. It should be pointed out that in commonly used magnetron sputtering methods as-deposited thin films are amorphous and receiving nanocrystalline structure is possible only after additional annealing treatment at high temperatures. However, thin films prepared with the aid of the Low Pressure Hot Target Reactive Sputtering (LPHTRS) process had anatase structure, while using the High Energy Reactive Magnetron Sputtering process (HERMS) lead to obtaining rutile coatings directly after deposition process. These sputtering methods are unique and protected by several patent applications e.g. ${ }^{38-40}$. Both deposition processes were conducted by sputtering Ti-Nd mosaic metallic targets in pure oxygen plasma and the working pressure was kept below $10^{-1} \mathrm{~Pa}^{38-40}$. Oxygen was used as the working and reactive gas. The main advantage of low pressure processes is a longer mean free path that allows oxygen ions to bombard the surface with much higher energy and as a result, small grains and nanocrystalline structure can be formed. During sputtering, the power released by the plasma allowed heating of the target surface close to the melting point. Increase of the target temperature favoured the stability of the discharge in transition mode and allowed the attainment of almost stoichiometric thin films ${ }^{41-43}$. The magnetron was powered by a pulsed power supply working in the unipolar mode with $165 \mathrm{kHz}$ sinusoidal pulses grouped with $1.6 \mathrm{kHz}$. The substrates were heated up to $570-680 \mathrm{~K}$ by radiation heaters. In HERMS process mentioned above, modifications were also used but the magnetron voltage amplitude was additionally increased from $1.2 \mathrm{kV}$ to $1.8 \mathrm{kV}$ and the cooling limitation of the sputtered target was applied ${ }^{38-40}$. Also some changes in the design of the applied supplier were introduced $^{\mathbf{4 4}}$. Increased nucleation energy of the atoms was assured by the simultaneously increased energy of the incoming ions. Ion bombardment during the film growth enhanced its densification and stimulated the crystal growth at the substrates. Due to these changes it was possible to increase the overall energy of the sputtered particles and increase the sputtering temperature that simultaneously enabled on receiving uniform films with nanocrystalline rutile structure directly after deposition (without annealing) ${ }^{\mathbf{4 5}}$.

The elemental composition of the prepared thin films was measured with the aid of FESEM FEI Nova Nano-
SEM 230 scanning electron microscope equipped with EDAX detector and the amount of neodymium was estimated to 1 at. $\%$.

The microstructure and crystal phases of $\mathrm{TiO}_{2}: \mathrm{Nd}$ thin films were determined by TECNAI $\mathrm{G}^{2}$ FEG Super-Twin $(200 \mathrm{kV})$ transmission electron microscope. Bright field (BFTEM) and high resolution (HRTEM) observations were performed. High quality TEM lamellas were prepared using the FEI Quanta 3D apparatus with the aid of focused ion beam $\left(\mathrm{Ga}^{+}, 30 \mathrm{kV}\right)$.

The photocatalytic properties of nanocrystalline $\mathrm{TiO}_{2}$ :Nd thin films were determined based on phenol decomposition reaction. The experimental setup consisted of the UV-Vis light source (6 x $20 \mathrm{~W}$ Phillips lamps with intensity of UV and Vis radiation: $183 \mathrm{~W} / \mathrm{m}^{2}$ and $167 \mathrm{~W} / \mathrm{m}^{2}$, respectively) and cylindrical reservoir, which contained $150 \mathrm{~mL}$ of solution with a phenol concentration of $10 \mathrm{mg} / \mathrm{L}$. To avoid the heating of the solution, the temperature was controlled by circulation of water through the jacket at a constant value of ca. $15^{\circ} \mathrm{C}$. In order to provide a good mixing of the suspension all experiments were carried out under agitation with a magnetic stirrer, operating at $1000 \mathrm{rpm}$. No external oxygen supply was used. No measurable degradation of the phenol occurred in the absence of $\mathrm{TiO}_{2}$ thin films. 30 minutes of premixing at a constant temperature in a dark condition was enough to achieve an adsorption/ desorption equilibrium and after that time the light was switched on to initiate the reaction. To determine the change of phenol concentration, samples were withdrawn from the reactor regularly every 60 minutes for 5 hours. The solutions were poured into a quartz cuvette and analyzed by OceanOptics QE 65000 UV-Vis spectrophotometer coupled with Mikropack DH-2000-BAL deuterium-halogen light source.

To determine the surface topography properties, the AFM measurements were performed by the UHV VT AFM/STM Omicron atomic force microscope operating in the ultra high vacuum conditions in the contact mode. X-Ray Photoelectron Spectroscopy (XPS) measurements were performed with the aid of a Specs Phoibos 100 MCD-5 (5 single channel electron multiplier) hemispherical analyzer using a Specs XR-50 X-ray source with $\mathrm{Mg} \mathrm{K} \alpha(1253.6 \mathrm{eV})$ beam. Measurements results were analyzed with the aid of CasaXPS software. All spectra were calibrated with respect to the binding energy of adventitious C1s peak at $284.8 \mathrm{eV}$. Analysis of the surface properties was completed by measurements of contact angle and critical surface tension, carried out with computer controlled Attension Theta Lite tensiometer. Liquids used for the contact angle determination were deionized water, ethylene glycol and ethanol. Contact angle measurements were performed according to the sessile drop method ${ }^{46}$. Those results were used to calculate the critical surface tension of $\mathrm{TiO}_{2}: \mathrm{Nd}(1.0$ at. $\%)$ thin films.

Optical properties were evaluated on the basis of transmission and reflection measurements. The experimental system was based on an Ocean Optics QE 65000 spectrophotometer and a coupled deuterium-halogen light source. On the basis of these measurements the analysis of the absorption coefficients and optical band gaps was performed. Additionally, the photoluminescence 
(PL) experiments were carried out at room temperature using an $\mathrm{Ar}^{+}$laser with $514.5 \mathrm{~nm}$ excitation wavelength and laser power equal to $15 \mathrm{~mW}$.

\section{RESULTS AND DISCUSSION}

The bright field transmission electron microscopy observations of the coatings prepared by LPHTRS method showed that the thin films had pseudo-columnar structure of anatase crystal lattice with visible voids between crystal columns (Fig. 1a). An amorphous area of the sawtooth shape of ca. $30 \mathrm{~nm}$ thick is present at the substrate-coating interface. In the case of $\mathrm{TiO}_{2}: \mathrm{Nd}$ thin films prepared by HERMS method, the densely packed, defected columnar structure of rutile crystal lattice was observed (Fig. 1b). Also for this sample, the thin amorphous layer of ca. $25 \mathrm{~nm}$ directly at the substrate-coating interface was noticed. The crystalline structure was formed after some time of sputtering and random nucleation of the crystalline phase during the magnetron sputtering process occurred.

a)

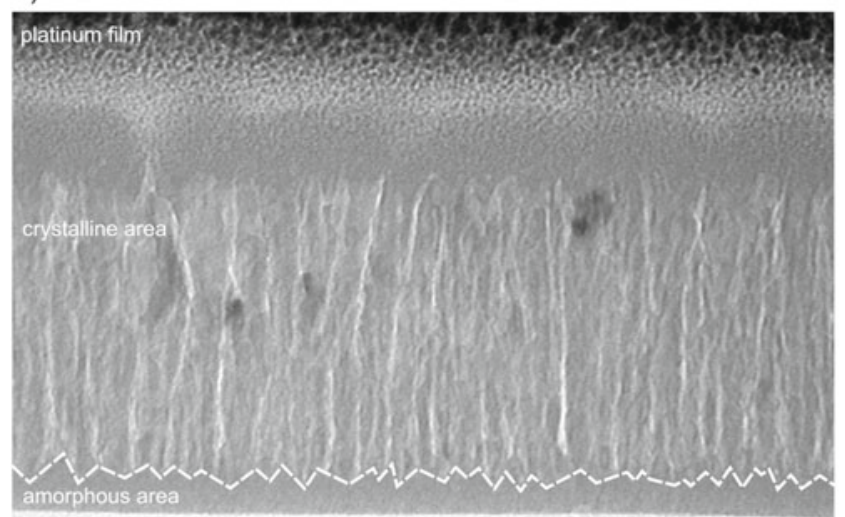

b)

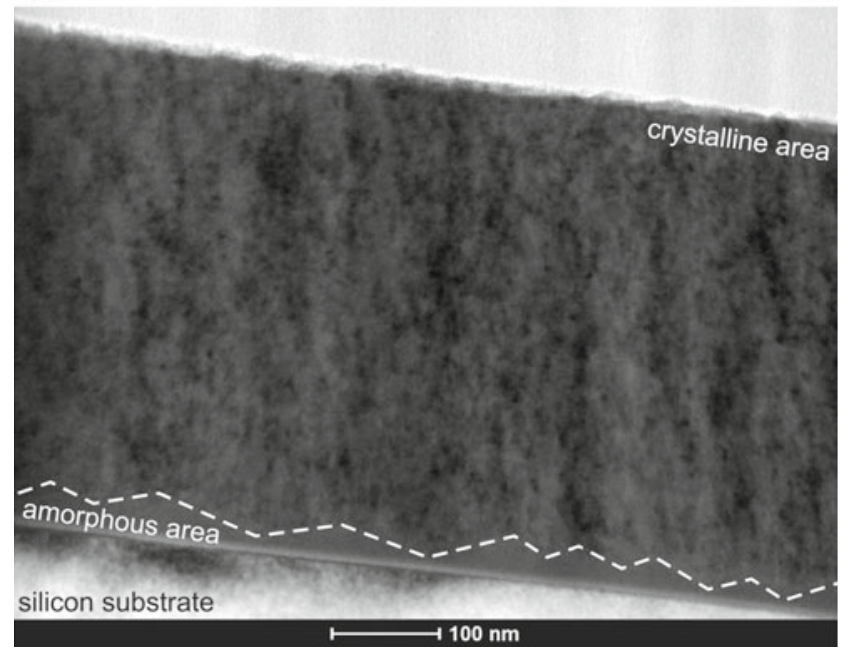

Figure 1. BFTEM images of the cross-section of $\mathrm{TiO}_{2}: \mathrm{Nd}$ [1.0 at. \%] thin films with: a) anatase and b) rutile structure

Further studies performed with a high resolution transmission electron microscopy (HRTEM) confirmed that prepared thin films consisted of a fine nanocrystalline structure that are shown in Figure 2. In the case a)

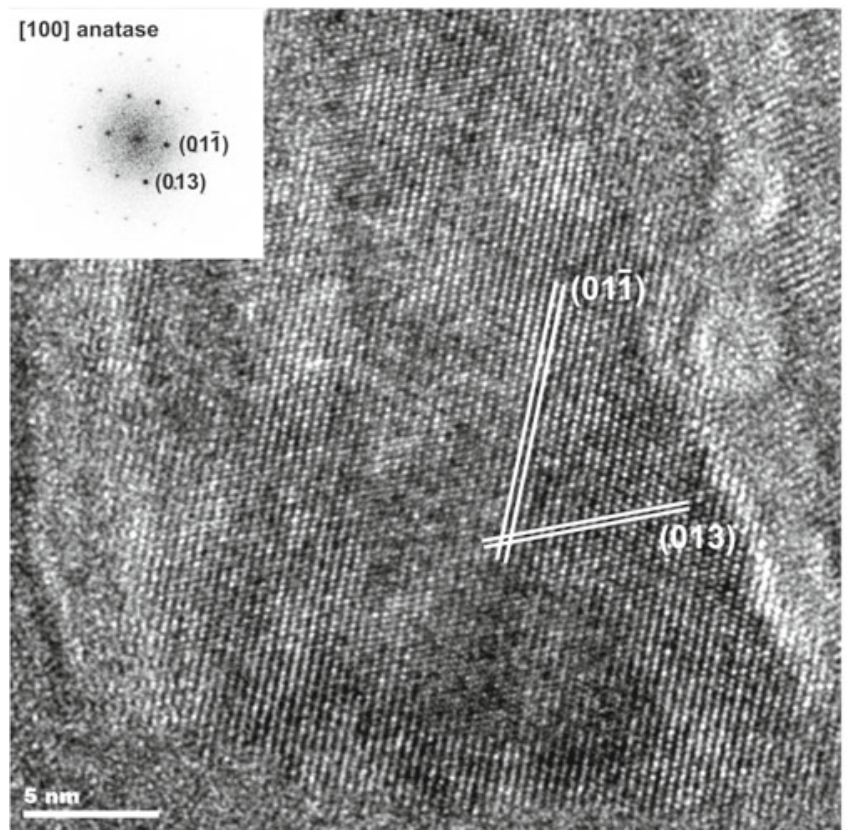

b)

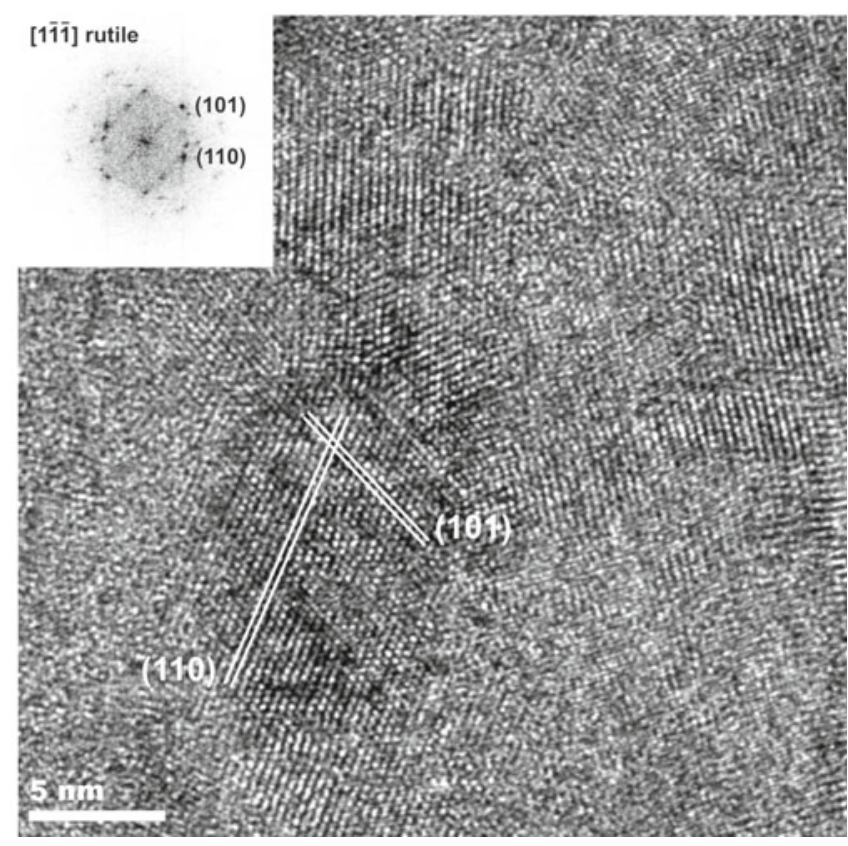

Figure 2. HRTEM images of $\mathrm{TiO}_{2}: \mathrm{Nd}[1.0$ at. \%] thin films with: a) anatase and b) rutile phase. The insets show the FFT diffraction patterns with marked lattice fringe spacings and proper planes

of $\mathrm{TiO}_{2}: \mathrm{Nd}$ thin films deposited by LPHTRS process (Fig. 2a) the visible lattice fringe spacings are equal to $3.55 \AA$ and $2.43 \AA$ which corresponds well with the separation between the $\left(\begin{array}{lll}0 & 1 & -1\end{array}\right)$ and $\left(\begin{array}{lll}0 & 1 & 3\end{array}\right)$ planes of the $\mathrm{TiO}_{2}$-anatase phase with the $\left[\begin{array}{lll}1 & 0 & 0\end{array}\right]$ zone axis, respectively. In Figure 2b HRTEM image of the coating deposited by HERMS process consisted of the lattice fringe spacings of $3.25 \AA$ and $2.54 \AA$ that comply with the separation of the $\left(\begin{array}{lll}1 & 1 & 0\end{array}\right)$ and $\left(\begin{array}{lll}1 & 0 & 1\end{array}\right)$ planes of the $\mathrm{TiO}_{2}$-rutile phase with the $[1-1-1]$ zone axis. Additionally, the FFT diffraction patterns presented as insets in HRTEM images were taken from the crystallites free from defects that allowed the precise evaluation of the lattice fringe spacings and angles between them. 
The requirement needed for the occurrence of the photocatalytic phenomenon of $\mathrm{TiO}_{2}$ is the presence of ultraviolet radiation. The activity of titania strongly depends on the quantity of generated electrons and holes, while the effectiveness of this process is determined by the possibility of separation, recombination, capturing and transfer of the carriers on the $\mathrm{TiO}_{2}$ surface ${ }^{47}$. The analysis of photocatalytic activity of materials based on titanium dioxide is often assessed on the basis of phenol decomposition measurements. The mechanism of phenol decomposition can be divided on direct decay on water, carbon dioxide and also on indirect products, that in further reactions are oxidized to harmless simple compounds. Therefore, on the surface of titania thin films there are two competitive processes and the decomposition of indirect compounds lasts considerably longer than decomposition of phenol itself. Hence, the overall decomposition is conditioned by the time of the degredation of indirect compounds.

The measured results of the phenol decomposition by $\mathrm{TiO}_{2}: \mathrm{Nd}(1.0$ at. $\%)$ are shown in Figure 3. In the case of the coatings with rutile structure, it was found that after 5 hours of the photocatalysis process $3.4 \%$ of phenol was decomposed. In turn, thin films doped with the same amount of neodymium, however with anatase structure, had higher photocatalytic activity and after 5 hours of the process up to $5.1 \%$ of phenol was decomposed. Higher photocatalytic activity of films with anatase structure structure as-compared to the rutile one is consistent with the results presented in the literaturee. eg. ${ }^{\mathbf{1 4}, \mathbf{4 8 - 5 0}}$.

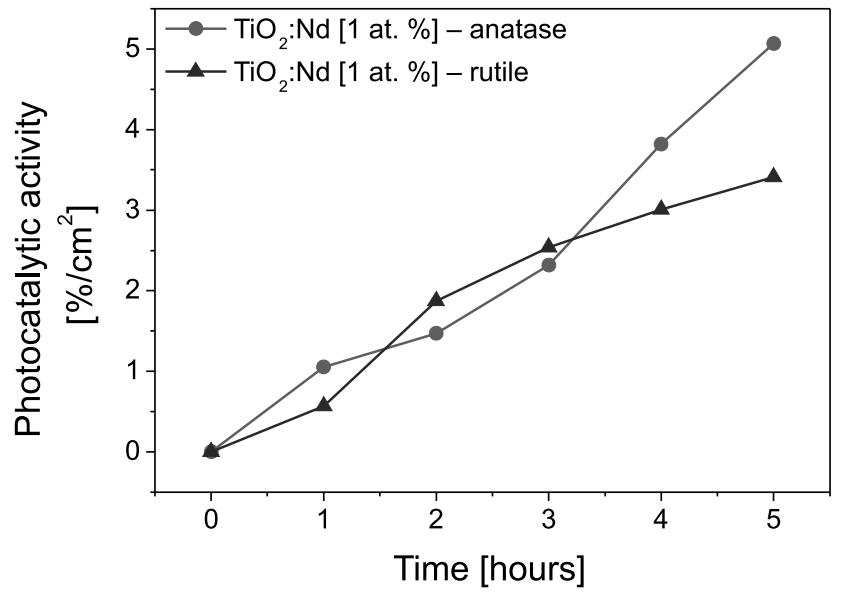

Figure 3. Photocatalytic activity of prepared $\mathrm{TiO}_{2}: \mathrm{Nd}[1.0$ at. \%] thin films with anatase and rutile structures based on phenol decomposition under UV-Vis light exposure

In photocatalysis the important factor is the wettability and the level of the adsorption of hydroxyl groups and water molecules by the film surface, especially in the case of thin-film coatings exposed to direct contact with moisture (e.g. rain) or located in an underwater environment. For this reason the wettability and adsoroption properties measurements were performed for prepared thin films. The wettability measurements were evaluated based on the contact angle of deionized water, ethylene glycol and ethanol droplets. For both thin films the contact angle of deionized water was below $90^{\circ}$, therefore these coatings were hydrophilic. The contact angle was slightly higher for the film with anatase structure than in the case of rutile. For the ethylene glycol and ethanol measurements negligible differences were also observed - this can testify about the similar wettability of $\mathrm{TiO}_{2}: \mathrm{Nd}$ thin films with various crystal structure. The images of droplets at the surface of thin films are presented in Figure 4.

Wettability of different solid materials can be characterized by the method proposed by Zisman ${ }^{46,51}$. Using a series of liquids with different surface tensions, a graph of $\cos \theta$ vs. $\gamma$ is determined. Critical surface tension equals the surface tension at which the plotted line intersects 1.0. It is often interpreted as the highest value of surface tension of a liquid that will completely wet the solid surface. The analysis of wettability measurements showed that critical surface tension for both measured thin films was similar and equal to ca. $20.2 \mathrm{mN} / \mathrm{m}$ (Fig. 4).

a)
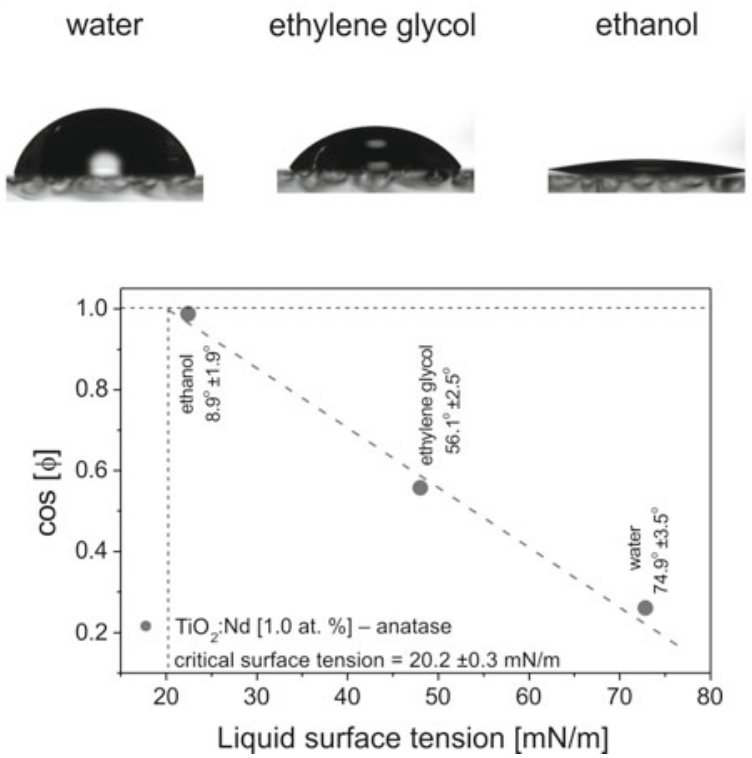

b)

water ethylene glycol ethanol
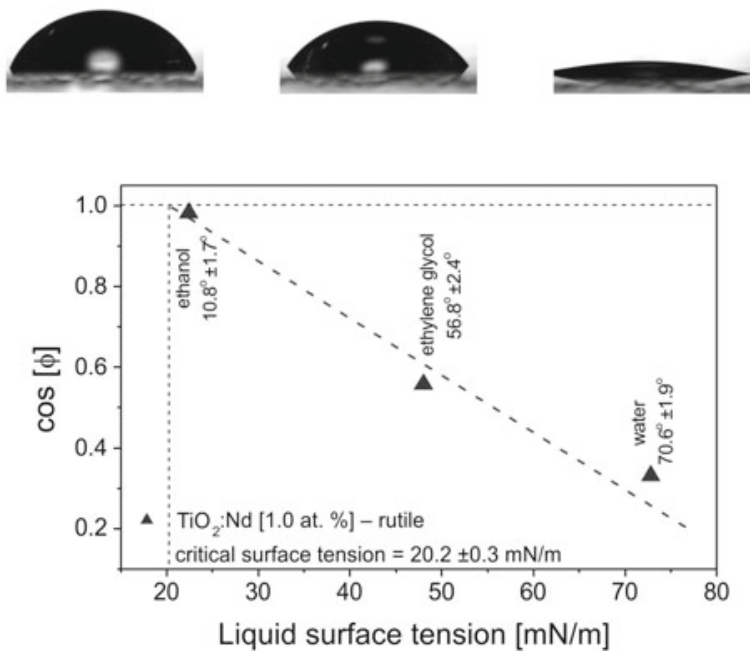

Figure 4. Deionized water, ethylene glycol and ethanol droplet images and Zisman plots presenting results of critical surface tension investigations of $\mathrm{TiO}_{2}: \mathrm{Nd}$ [1.0 at. \%] thin films with: a) anatase and b) rutile crystal phases

Wettability is not the only factor that influences the photocatalytic activity of thin films. In this case, the development of surface roughness (RMS - Root Mean Square) or ability to attach hydroxyl groups and water 
molecules are also crucial. In order to investigate the surface topography and its roughness, the AFM measurements were carried out. In Figure 5 the surface images of $\mathrm{TiO}_{2}: \mathrm{Nd}(1.0$ at. \%) thin films are presented. The measurements showed that in both films the distribution of nanocrystalline grains was homogenous. However, anatase thin films exhibited much smaller grains than rutile coatings. The height distribution of grain size (Fig. 6) showed the diversification of the thin film surface. The RMS roughness was slightly higher for thin films with anatase structure as-compared to the rutile one.

a)
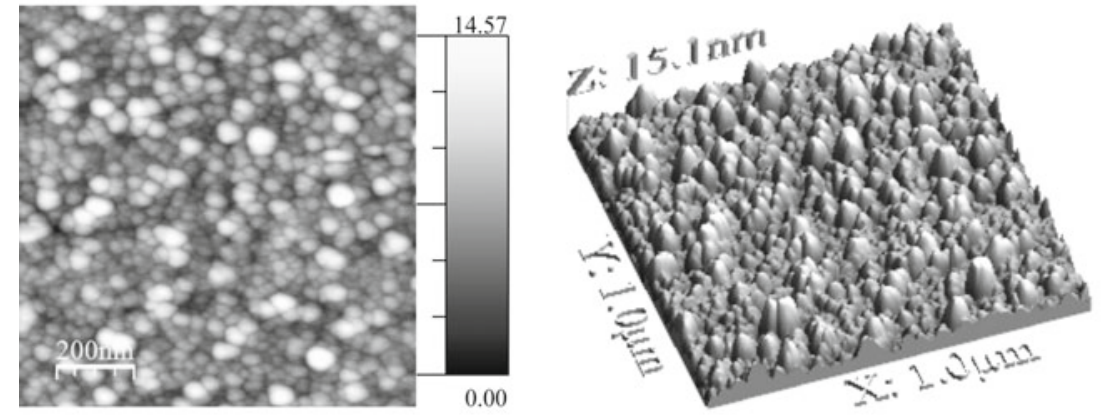

b)

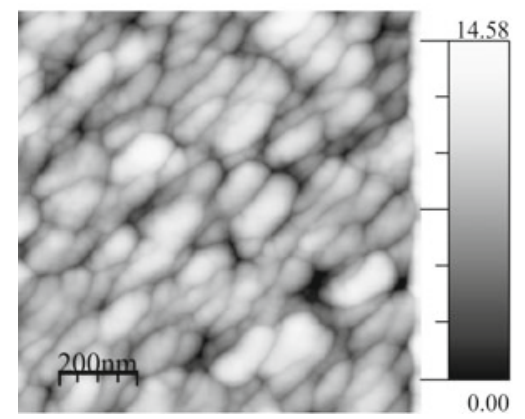

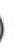

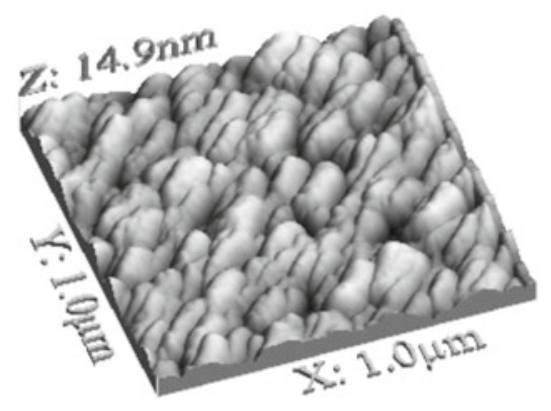

the separation energy width equal to $5.8 \mathrm{eV}$ between the $\mathrm{Ti} 2 \mathrm{p}_{3 / 2}$ and $\mathrm{Ti} 2 \mathrm{p}_{1 / 2}$ peaks indicate the $\mathrm{Ti}^{4+}$ oxidation state, which in turn testifies to the formation of $\mathrm{TiO}_{2}{ }^{\mathbf{5 2}}$. The position of $\mathrm{Nd} 4 \mathrm{~d}$ peaks at XPS spectra indicates the formation of the $\mathrm{Nd}^{3+}$ oxidation state and therefore presence of neodymium oxide $\left(\mathrm{Nd}_{2} \mathrm{O}_{3}\right)^{\mathbf{5 2}}$. Results obtained for O1s oxidation state revealed that on the surface of both thin films water molecules $\left(\mathrm{H}_{2} \mathrm{O}_{\text {ads }}\right)$ and hydroxyl radicals $\left(\mathrm{OH}^{-}\right)$were adsorbed. The summarized level of adsorbed water molecules and hydroxyl radicals (to the whole signal obtained for oxygen) was equal to ca.

Figure 5. AFM images of $\mathrm{TiO}_{2}: \mathrm{Nd}$ [1.0 at. \%] thin films with: a) anatase and b) rutile crystal phases

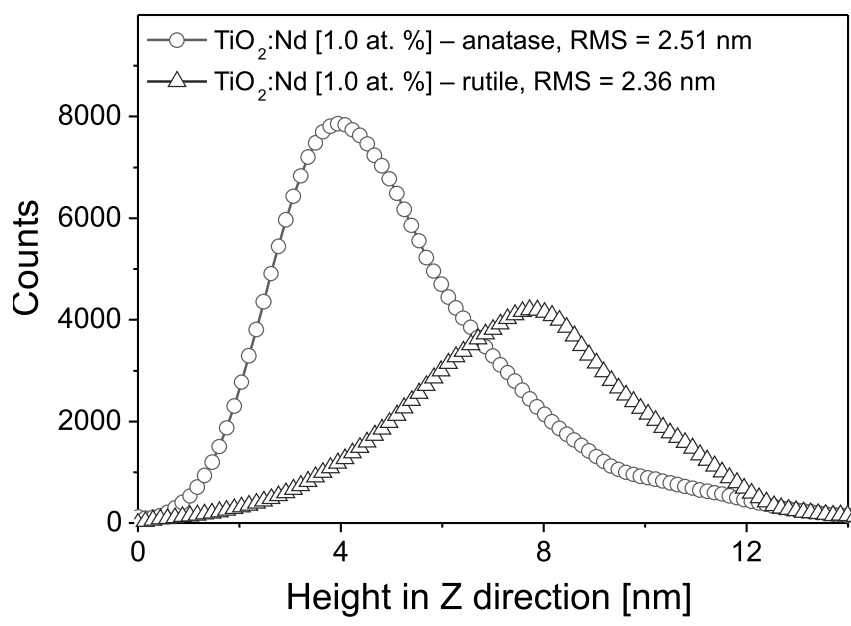

Figure 6. Height distribution of grains in $\mathrm{Z}$ direction of $\mathrm{TiO}_{2}: \mathrm{Nd}$ [1.0 at. \%] thin films with their surface roughness (RMS factor)

XPS studies were performed to determine the chemical states and ability to adsorb hydroxyl groups and water molecules on the surface of prepared $\mathrm{TiO}_{2}: \mathrm{Nd}$ thin films. In Figure 7 the Ti2p, O1s and $\mathrm{Nd} 4 \mathrm{~d}$ core level spectra are presented for coatings with anatase and rutile structures. The position of the Ti2p doublet and
$57.6 \%$ and $35.3 \%$ for thin films with anatase and rutile structures, respectively.

$\mathrm{TiO}_{2}: \mathrm{Nd}$ thin films with anatase and rutile structures are well transparent in the visible light range and the transparency level is similar for both samples. Transmittance spectra of prepared coatings are shown in Figure 8. Addition of $\mathrm{Nd}$ dopant to titanium dioxide does not deteriorate its high transparency. The cut-off wavelength of the film with anatase structure is shifted towards shorter waves as-compared to the rutile one and equal to $330 \mathrm{~nm}$ and $352 \mathrm{~nm}$, respectively. Ability to absorb UV light by thin films is crucial for photocatalytic activity. Taking into consideration the transmittance spectra of $\mathrm{TiO}_{2}: \mathrm{Nd}(1.0$ at. \%), the absorption spectra were determined using Bouger-Lambert-Beer equation ${ }^{\mathbf{5 3}}$ :

$\alpha(\lambda)=-\frac{\ln \left[T_{\lambda}(\lambda)\right]}{g}$

where: $a$ - absorption coefficient, $g$ - thin film thickness.

The absorption spectra of $\mathrm{TiO}_{2}: \mathrm{Nd}$ thin films with anatase and rutile structure are presented in Figure 9. In the background the spectrum of UV-Vis lamp that was used during the photocatalysis process is also shown. The cut-off wavelength of $\mathrm{TiO}_{2}: \mathrm{Nd}(1.0 \%$ at.) coatings with anatase structure is shifted towards the UV region 
a)
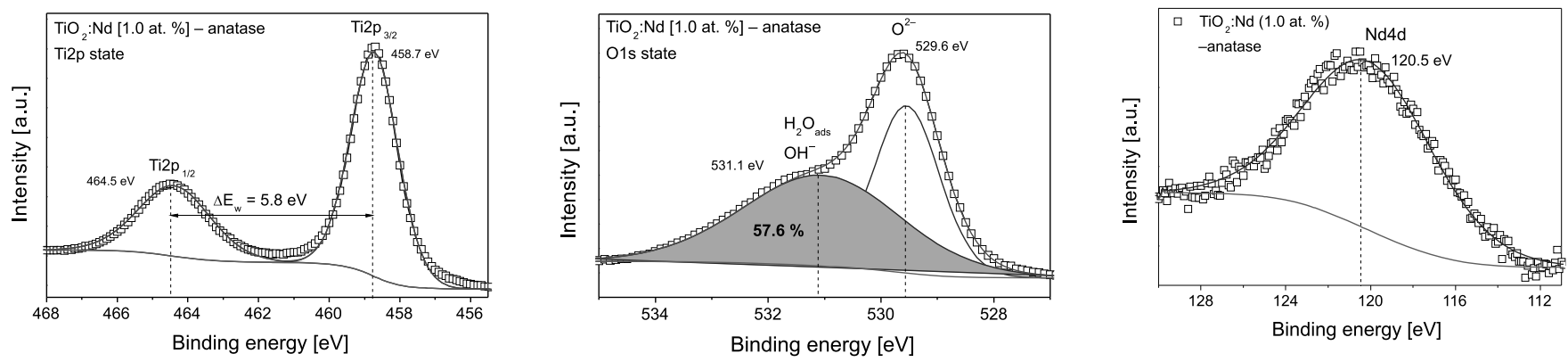

b)
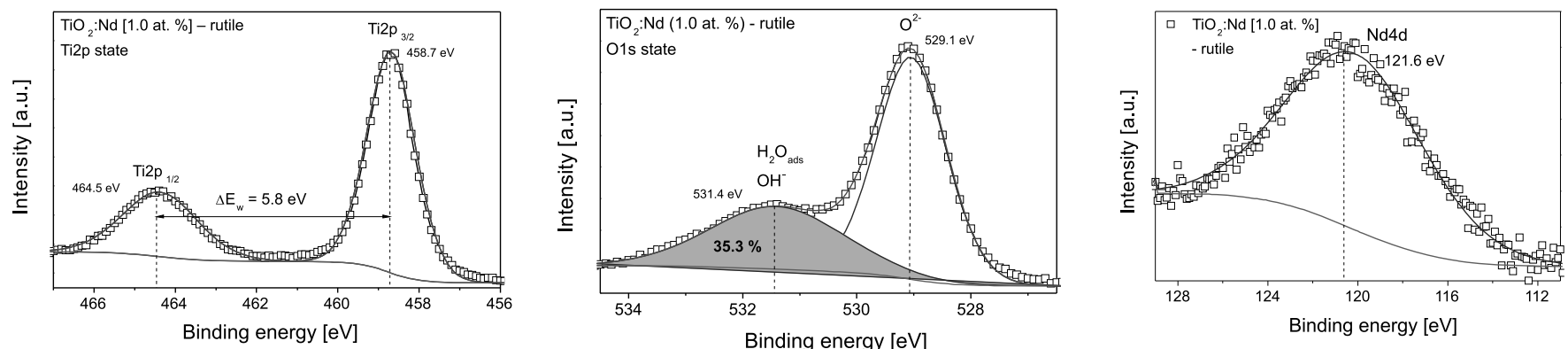

Figure 7. XPS spectra of Ti2p (left side), O1s (centre) and $\mathrm{Nd} 4 \mathrm{~d}$ (right side) core levels for $\mathrm{TiO}_{2}: \mathrm{Nd}$ [1.0 at. \%] thin films with: a) anatase and b) rutile crystal phases

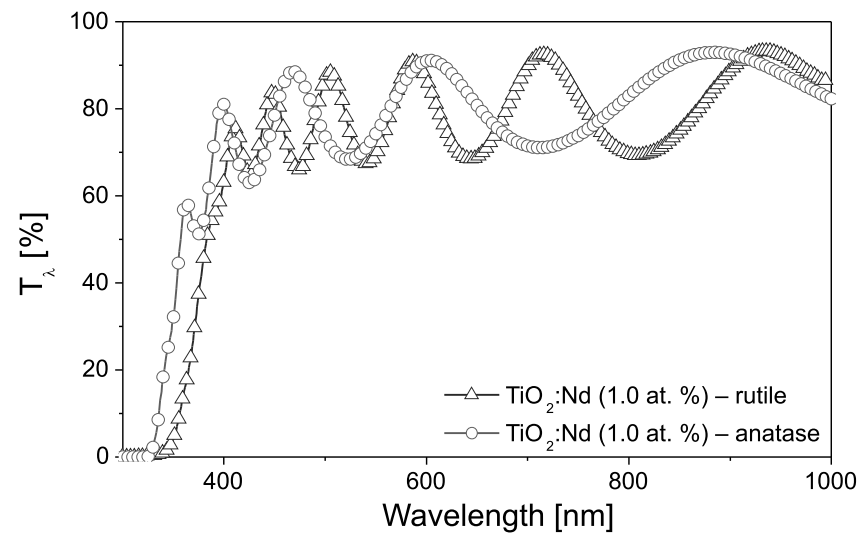

Figure 8. Comparison of transmittance spectra of $\mathrm{TiO}_{2}: \mathrm{Nd}$ [1.0 at. \%] with anatase and rutile structure

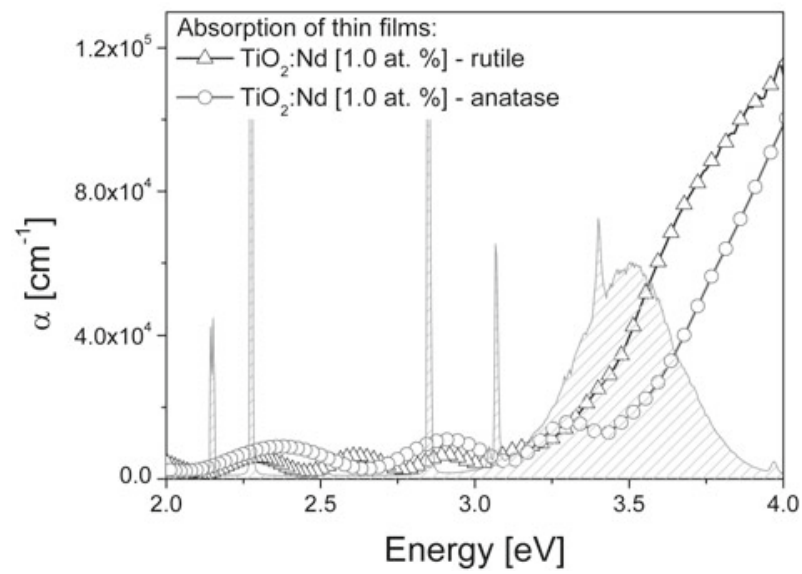

Figure 9. Absorption spectra of $\mathrm{TiO}_{2}: \mathrm{N}[1.0$ at. \%] thin films with anatase and rutile structure in comparison with the spectrum of UV-Vis lamp that was used for photocatalytic experiment as compared to the rutile films and therefore absorb less light. Titanium dioxide is the material with allowed indirect transitions that can be determined from the Tauc equation ${ }^{\mathbf{5}}$. Such plots are shown in Figure 10. The calculated optical band gaps for thin films with anatase and rutile structures are equal to 3.23 and $3.11 \mathrm{eV}$, respectively. Obtained results are in good correlation with the cut-off wavelength measurements, while the shorter and simultaneously the larger optical band gap were determined for $\mathrm{TiO}_{2}: \mathrm{Nd}$ thin films with anatase structure.

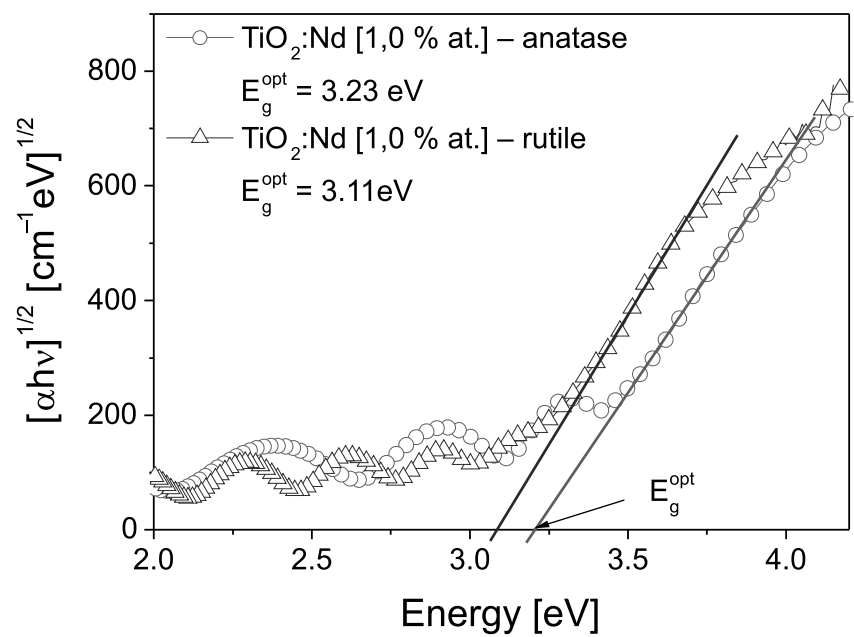

Figure 10. Tauc plots for allowed indirect transitions in the function of energy of $\mathrm{TiO}_{2}: \mathrm{Nd}$ thin films. $\mathrm{E}_{\mathrm{g}}{ }^{\text {opt }}$ stands for the value of optical band gap

The recombination rate of the investigated $\mathrm{TiO}_{2}: \mathrm{Nd}$ coatings should inversely affect the photoluminescence spectra in comparison to photocatalytic activity. Jing et al. ${ }^{55}$ stated that the photoluminescence should be higher for materials with lower photocatalytic activity. In Figure 11 the photoluminescence spectra of $\mathrm{TiO}_{2}: \mathrm{Nd}$ thin films with anatase and rutile structure were compared 


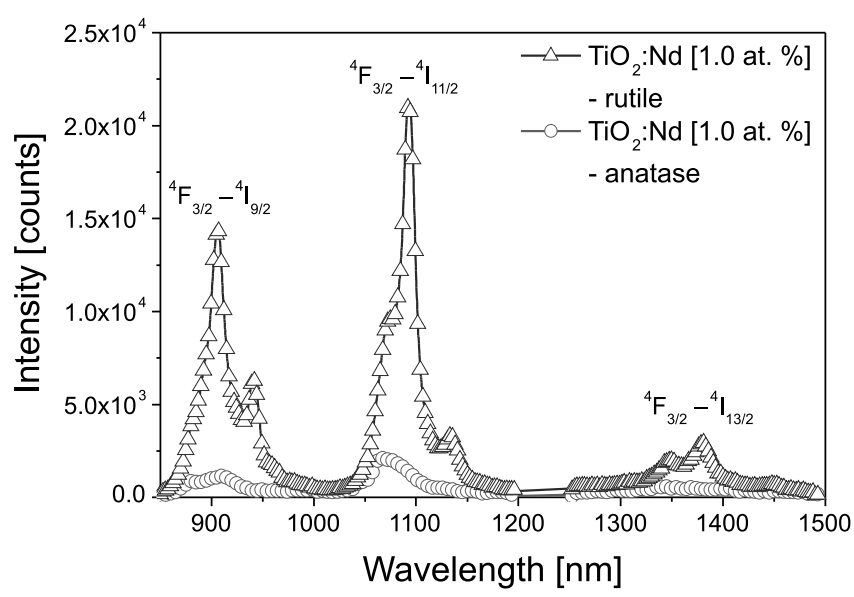

Figure 11. Comparison of photoluminescence spectra of radiative recombination of carriers between various energy levels for $\mathrm{TiO}_{2}: \mathrm{Nd}[1.0$ at. \%] thin films with different crystal phases

for electron transitions between ${ }^{4} \mathrm{~F}_{3 / 2}-{ }^{4} \mathrm{I}_{9 / 2},{ }^{4} \mathrm{~F}_{3 / 2}-{ }^{4} \mathrm{I}_{11 / 2}$, ${ }^{4} \mathrm{~F}_{3 / 2}-{ }^{4} \mathrm{I}_{13 / 2}$ energy levels. The much higher photoluminescence intensity was observed for thin films with rutile structure, what is in good correlation with Jing theory. Such difference in the photoluminescence intensity caused by energy transfer efficiency could be explained by different host-to- $\mathrm{Ln}^{3+}$ energy transfer pathway. In the case of investigated titania with anatase, phase broad emission peaks were found which are characteristic for self-trapped exciton defects ${ }^{\mathbf{5 6}}$. Therefore, due to these defects, the competitive energy transfer processes from the $\mathrm{TiO}_{2}$-anatase conducting band to the self-trapped exciton defects and $\mathrm{Nd}^{3+}$ energy states may appear and for this reason lower photoluminescence intensity can be observed ${ }^{56}$.

Presented results have shown that thin films with anatase structure exhibited better photocatalytic activity than rutile coatings. Both thin films had very similar wettability and were well transparent in the measured wavelength range, while a wider optical band gap was determined for anatase film. Such a result indicates that the anatase coating absorbs less light in the UV region and therefore should exhibit a lower photocatalytic activity. However, surface topography investigations performed by AFM revealed that in the case of anatase films more developed surface with significantly smaller grains and higher RMS roughness was obtained. This can suggest that a larger active surface area was taking part in the photocatalysis process for anatase coatings. Also XPS measurements testify to the very good water adsorption of anatase thin films surface (ca. 30\% higher in comparison to rutile films) that could also lead to the improvement of the photocatalytic activity. Additionally, the photoluminescence measurements pointed out that in the case of $\mathrm{TiO}_{2}: \mathrm{Nd}$ thin films with rutile structure, the efficiency of electron/hole recombination is much greater than in the case of anatase film. Therefore, the emission intensity is higher, however simultaneously the photocatalytic activity is lower. It seems that this could be a contributing factor as to why the photocatalytic activity of the anatase coating was improved as-compared to the rutile one.

\section{SUMMARY}

To obtain various crystalline structures of titanium dioxide thin films doped with 1.0 at. \% of neodymium, two different magnetron sputtering processes were used. Thin films of anatase phase were prepared using Low Pressure Hot Target Reactive Sputtering process, while rutile films were obtained by High Energy Reactive Magnetron Sputtering Process. The research of the microstructure revealed the fibrous structure of the anatase thin film and densely packed columnar structure in case of rutile one.

Photocatalytic activity of the thin films in the anatase phase was greater as-compared to the rutile coatings. The phenol decomposition after 5 hours of the photocatalytic process was equal to $5.1 \%$ and $3.4 \%$ for films with anatase and rutile phases, respectively. The wettability and surface roughness of these coatings were similar, however anatase thin films exhibited greater ability to adsorb hydroxyl groups and water molecules on the surface.

Optical measurements showed that both thin films were well transparent with the transmission factor in the visible wavelength range equal to ca. $80 \%$. The cut-off wavelength was shifted towards the ultraviolet wavelength for thin films with anatase phase. Therefore the larger optical energy band gap was obtained for the film with anatase structure and was equal to $3.23 \mathrm{eV}$, while for rutile was $3.11 \mathrm{eV}$. Both thin films due to their exceptional transparency and photocatalytic activity could be used for e.g. self-cleaning: windows, touch panels or glasses.

\section{ACKNOWLEDGMENTS}

This work was financed from the sources granted by the NCN as a research project number DEC-2012/05/N/ ST7/00173, DEC-2012/07/B/ST8/03760 and as a PhD scholarship number DEC-2013/08/T/ST7/00131.

\section{LITERATURE CITED}

1. Saif, M. \& Abdel-Mottaleb, M.S.A. (2007). Titanium dioxide nanomaterial doped with trivalent lanthanide ions of $\mathrm{Tb}, \mathrm{Eu}$ and Sm: Preparation, characterization and potential applications, Inorg. Chim. Acta 360, 2863-2874. DOI: 10.1016/j. ica.2006.12.052.

2. Radecka, M., Gorzkowska-Sobaś, A., Zakrzewska, K. \& Sobaś, P. (2004). Nanocermet $\mathrm{TiO}_{2}$ :Au thin film electrodes for wet electrochemical solar cells, Opto-Electron. Rev. 12, 53-56.

3. Mazur, M., Wojcieszak, D., Domaradzki, J., Kaczmarek, D., Song, S. \& Placido, F. (2013). $\mathrm{TiO}_{2} / \mathrm{SiO}_{2}$ multilayer as an antireflective and protective coating deposited by microwave assisted magnetron sputtering, Opto-Electron. Rev. 21(2), 233-238. DOI: 10.2478/s11772-013-0085-7.

4. Comini, E., Ferroni, M., Guidi, V., Vomiero, A., Merli, P.G., Morandi, V., Sacerdoti, M., Della Mea, G. \& Sberveglieri, G. (2005). Effects of Ta/Nb-doping on titania-based thin films for gas-sensing, Sensor. Actuat. B 108, 21-28. DOI: 10.1016/j. snb.2004.10.041.

5. Ruiz, A.M., Cornet, A., Shimanoe, K., Morante, J.R. \& Yamazoe, N. (2005). Effects of various metal additives on the gas sensing performances of $\mathrm{TiO}_{2}$ nanocrystals obtained from hydrothermal treatments, Sensor. Actuat. B 108, 34-40. DOI: 10.1016/j.snb.2004.09.045.

6. Janus, M. \& Morawski, A.W. (2007). New method of improving photocatalytic activity of commercial Degussa P25 for 
azo dyes decomposition. Appl. Catal. B Environ. 75, 118-123. DOI: $10.1016 /$ j.apcatb.2007.04.003.

7. Bubacz, K., Choina, J., Dolat, D., Borowiak-Palen, E., Moszynski, D. \& Morawski, A.W. (2010). Studies on nitrogen modified $\mathrm{TiO}_{2}$ photocatalyst prepared in different conditions, Mater. Res. Bull. 45, 1085-1091. DOI: 10.1016/j.materresbull.2010.06.024.

8. Dolat, D., Mozia, S., Wróbel, R.J., Moszynski, D., Ohtani, B., Guskos, N. \& Morawski, A.W. (2015). Nitrogen-doped, metal-modified rutile titanium dioxide as photocatalysts for water remediation. Appl. Catal. B Environ. 162, 310-318. DOI: 10.1016/j.apcatb.2014.07.001.

9. Eufinger, K., Poelman, D., Poelman, H., Gryse, De R. \& Marin, G.B. (2007). Photocatalytic activity of dc magnetron sputter deposited amorphous $\mathrm{TiO}_{2}$ thin films, Appl. Surf. Sci. 254, 148-152. DOI: 10.1016/j.apsusc.2007.07.009.

10. Verma, A., Samanta, S. B., Bakhshi, A.K., Agnihotry, S.A. (2005). Effect of stabilizer on structural, optical and electrochemical properties of sol-gel derived spin coated $\mathrm{TiO}_{2}$ films, Sol. Energ. Mater. Sol. C. 88, 47-64. DOI: 10.1016/j. solmat.2004.10.006.

11. Zhang, J.Y., Boyd, I.W., O’Sullivan, B.J., Hurley, P.K., Kelly, P.V. \& Senateur, J.P. (2002). Nanocrystalline $\mathrm{TiO}_{2}$ films studied by optical, XRD and FTIR spectroscopy, J. Non-Cryst. Solids 303, 134-138. DOI: 10.1016/S0022-3093(02)00973-0.

12. Xie Y., Ma Z., Liu L., Su Y., Zhao H., Liu Y., Zhang Z., Duan H., Li J., Xiea E. (2010). Oxygen defects-modulated green photoluminescence of Tb-doped $\mathrm{ZrO}_{2}$. Appl. Phys. Lett. 97(141916), 1-3. DOI: 10.1063/1.3496471.

13. Park, B. (2007). Current and Future Applications of Nanotechnology, Iss. Environ. Sci. Technol. 24, 1-18, The Royal Society of Chemistry.

14. Chen, L., Graham, M.E., Li, G., Gray, K.A. (2006). Fabricating highly active mixed phase $\mathrm{TiO}_{2}$ photocatalysts by reactive DC magnetron sputter deposition, Thin Solid Films 515, 1176-1181. DOI: 10.1016/j.tsf.2006.07.094.

15. Mellott, N.P., Durucan, C., Pantano, C.G., Guglielmi, M. (2006). Commercial and laboratory prepared titanium dioxide thin films for self-cleaning glasses: Photocatalytic performance and chemical durability, Thin Solid Films 502, 112-120. DOI: 10.1016/j.tsf.2005.07.255.

16. Wu, K.R., Wang, J.J., Liu, W.C., Chen, Z.S. \& Wu, J.K. (2006). Deposition of graded $\mathrm{TiO}_{2}$ films featured both hydrophobic and photo-induced hydrophilic properties, Appl. Surf. Sci. 252, 5829-5838. DOI: 10.1016/j.apsusc.2005.08.016.

17. Yuan, M., Zhang, J., Yan, S., Luo, G., Xu, Q., Wang, X. \& Li, C. (2011). Effect of $\mathrm{Nd}_{2} \mathrm{O}_{3}$ addition on the surface phase of $\mathrm{TiO}_{2}$ and photocatalytic activity studied by UV Raman spectroscopy. J. Alloy. Compd. 509, 6227-6235. DOI: 10.1016/j. jallcom.2011.03.010.

18. Kralchevska, R., Milanova, M., Hristov, D., Pintar, A. \& Todorovsky, D. (2012). Synthesis, characterization and photocatalytic activity of neodymium, nitrogen and neodymium-nitrogen doped $\mathrm{TiO}_{2}$. Mat. Res. Bull. 47, 2165-2177. DOI: 10.1016/j.materresbull.2012.06.009.

19. Xie, Y. \& Yuan, C. (2005), Photocatalytic and photoelectrochemical performance of crystallized titanium dioxide sol with neodymium ion modification. J. Chem. Technol. Biot. 90, 954-963. DOI: 10.1002/jctb.1270.

20. Burns, A., Li, W., Baker, C. \& Shah, S.I. (2002). Sol-gel synthesis and characterization of neodymium-ion doped nanostructured titania thin films. Mat. Res. Soc. Symp. Proc. 703, V5.2.1-V5.2.6. DOI: 10.1557/PROC-703-V5.2.

21. Wojcieszak, D., Kaczmarek, D., Domaradzki, J., Mazur, M., Morawski, A., Janus, M., Prociów, E. \& Gemmellaro, P. (2012). Photocatalytic properties of transparent $\mathrm{TiO}_{2}$ coatings doped with neodymium, Pol. J. Chem. Technol. 14(3), 1-7. DOI: $10.2478 / \mathrm{v} 10026-012-0077-2$.

22. Wojcieszak, D., Kaczmarek, D., Domaradzki, J. \& Mazur, M. (2013). Correlation of Photocatalysis and Photoluminescence
Effect in Relation to the Surface Properties of $\mathrm{TiO}_{2}$ : $\mathrm{Tb}$ Thin Films, Int. J. Photoenergy 2013, Article ID 526140. http://dx.doi. org $/ 10.1155 / 2013 / 526140$

23. Wojcieszak, D., Mazur, M., Kurnatowska, M., Kaczmarek, D., Domaradzki, J., Kępiński, L. \& Chojnacki, K. (2014). Influence of Nd-Doping on Photocatalytic Properties of $\mathrm{TiO}_{2}$ Nanoparticles and Thin Film Coatings, Int. J. Photoenergy 2014, Article ID 463034. http://dx.doi.org/10.1155/2014/463034

24. Tryba, B., Morawski, A.W., Inagaki, M. \& Toyoda, M. (2006). Mechanism of phenol decomposition on $\mathrm{Fe}-\mathrm{C}-\mathrm{TiO}_{2}$ and $\mathrm{Fe}-\mathrm{TiO}_{2}$ photocatalysts via photo-Fenton process, $J$. Photoch. Photobio. A 179, 224-228. DOI: 10.1016/j.jphotochem.2005.08.019

25. Jiang, X., Yang, L., Liu, P., Li, X. \& Shen, J. (2010). The photocatalytic and antibacterial activities of neodymium and iodine doped $\mathrm{TiO}_{2}$ nanoparticles, Colloid. Surface B 79, 69-74. DOI:10.1016/j.colsurfb.2010.03.031

26. Khalid, N.R., Ahmed, E., Hong, Z., Zhang, Y., Ullah, M., Ahmed, M. (2013). Graphene modified $\mathrm{Nd} / \mathrm{TiO}_{2}$ photocatalyst for methyl orange degradation under visible light irradiation, Ceram. Int. 39, 3569-3575. DOI: 10.1016/j.ceramint.2012.10.183.

27. Bokare, A., Sanap, A., Pai, M, Sabharwal, S., Athawale, A.A. (2013). Antibacterial activities of $\mathrm{Nd}$ doped and Ag coated $\mathrm{TiO}_{2}$ nanoparticles under solar light irradiation, Colloid. Surface. B 102, 273- 280. DOI: 10.1016/j.colsurfb.2012.08.030.

28. Rengaraj, S., Venkataraj, S., Yeon, J.W., Kim, Y., Li, X.Z., Pang, G.K.H. (2007). Preparation, characterization and application of $\mathrm{Nd}-\mathrm{TiO}_{2}$ photocatalyst for the reduction of Cr(VI) under UV light illumination. Appl. Catal. B. Environ. 77, 157-165. DOI: 10.1016/j.apcatb.2007.07.016.

29. Kim, W.S., Ha, S.M., Yun, S. \& Park, H.H. (2002). Microstructure and electrical properties of $\mathrm{Ln}_{2} \mathrm{Ti}_{2} \mathrm{O}_{7}(\mathrm{Ln}=\mathrm{La}$, Nd), Thin Solid Films 420, 575-578. DOI: 10.1016/S00406090(02)00837-4.

30. Eufinger, K., Tomaszewski, H., Depla, D., Poelman, H., Poelman, D., De Gryse, R. (2006). The d.c. magnetron sputtering behavior of $\mathrm{TiO}_{2-\mathrm{x}}$ targets with added $\mathrm{Fe}_{2} \mathrm{O}_{3}$ or $\mathrm{Nd}_{2} \mathrm{O}_{3}$, Thin Solid Films 515, 683-686. DOI: 10.1016/j.tsf.2005.12.241.

31. Pandiyan, R., Bartali, R., Micheli, V., Gottardi, G., Luciu, I., Ristic, D., Goget, G.A., Ferrari, M. \& Laidani, N. (2011). Influence of $\mathrm{Nd}^{3+}$ doping on the structural and near-IR photoluminescence properties of nanostructured $\mathrm{TiO}_{2}$ films, Energy Procedia 10, 167-171. DOI: 10.1016/j.egypro.2011.10.171.

32. Shao, Z., Saitzek, S., Roussel, P., Huvé, M., Desfeux, R., Mentré, O. \& Abraham, F. (2009). An easy sol-gel route for deposition of oriented $\mathrm{Ln}_{2} \mathrm{Ti}_{2} \mathrm{O}_{7}(\mathrm{Ln}=\mathrm{La}, \mathrm{Nd})$ films on $\mathrm{SrTiO}_{3}$ substrates, J. Cryst. Growth 311, 4134-4141. DOI: 10.1016/j.jcrysgro.2009.06.051.

33. Song, Y.J., Ferroelectric Thin Films for High Density Non-volatile Memories, Virgina Polytechnic Institute and State University, Blacksburg, 1998 (Ph. D. Thesis).

34. Havelia, S., Balasubramaniam, K.R., Spurgeon, S., Cormack, F. \& Salvador, P.A. (2008). Growth of $\mathrm{La}_{2} \mathrm{Ti}_{2} \mathrm{O}_{7}$ and $\mathrm{LaTiO}_{3}$ thin films using pulsed laser deposition, J. Cryst. Growth 310, 1985-1990. DOI: 10.1016/j.jcrysgro.2007.12.006.

35. Kannan, P.K., Saraswathi, R. \& Rayappan, J.B.B. (2010). A highly sensitive humidity sensor based on DC reactive magnetron sputtered zinc oxide thin film, Sens. Actuat. A Phys. 164, 8-14. DOI: 10.1016/j.sna.2010.09.006.

36. Kleinhempel, R., Wahl, A. \& Thielsch, R. (2011). Large area AR coating on plastic substrate using roll to roll methods, Surf. Coat. Technol. 205, S502-S505. DOI: 10.1016/j. surfcoat.2010.10.064.

37. Szczyrbowski, J., Dietrich, A. \& Hartig, K. (1989). Bendable silver-based low emissivity coating on glass, Sol. Energ. Mater. 19, 43-53. DOI: 10.1016/0165-1633(89)90022-1.

38. Domaradzki, J., Kaczmarek, D. \& Prociow, E.L. Patent PL 210206, 2011.

39. Prociów, E., Domaradzki, J., Kaczmarek, D. \& Berlicki, T. Patent PL 211827, 2012. 
40. Prociów, E., Domaradzki, J., Kaczmarek, D. \& Berlicki, T. Patent PL 212461, 2012.

41. Billard, A., Mercs, D., Perry, F. \& Frantz, C. (1999). Influence of the target temperature on a reactive sputtering process, Surf. Coat. Technol. 116-119, 721-726. DOI:10.1016/ S0257-8972(99)00261-3.

42. Wasielewski, R., Domaradzki, J., Wojcieszak, D., Kaczmarek, D., Borkowska, A., Prociow, E. \& Ciszewski, A. (2008). Surface characterization of $\mathrm{TiO}_{2}$ thin films obtained by high-energy reactive magnetron sputtering, Appl. Surf. Sci. 254, 4396-4400. DOI: 10.1016/j.apsusc.2008.01.017.

43. Domaradzki, J., Kaczmarek, D., Prociow, E., Borkowska, A., Schmeisser, D. \& Beuckert, G. (2006). Mircrostructure and optical properties of $\mathrm{TiO}_{2}$ thin films prepared by low pressure hot target reactive magnetron sputtering, Thin Solid Films 513, 269-274. DOI: 10.1016/j.apsusc.2008.01.017.

44. Posadowski, W.M., Wiatrowski, A., Dora, J. \& Radzimski, Z.J. (2008). Magnetron sputtering process control by medium-frequency power supply parameter, Thin Solid Films 516, 4478-4482. DOI: 10.1016/j.tsf.2007.05.077.

45. Kaczmarek, D., Domaradzki, J., Wojcieszak, D., Prociów, E., Mazur, M. \& Placido, F. Lapp S. (2012). Hardness of nanocrystalline $\mathrm{TiO}_{2}$ thin films, J. Nano Res. 18/19, 195-200. DOI: 10.4028/www.scientific.net/JNanoR.18-19.195.

46. Kwok, D.Y., Neumann, A.W. (1999). Contact angle measurement and contact angle interpretation. Adv. Coll. Interfac. 81, 167-249. DOI: 10.1016/S0001-8686(98)00087-6.

47. Liqiang, J., Yichun, Q., Baiqi, W., Shudan, L., Baojiang, J., Libin, Y., Wei, F., Honggang, F. \& Jiazhong, S. (2006), Review of photoluminescence performance of nano-sized semiconductor materials and its relationships with photocatalytic activity, Sol. Energ. Mater. Sol. C 90, 1773-1787. DOI: 10.1016/j. solmat.2005.11.007.

48. Choi, W. (2006), Pure and modified $\mathrm{TiO}_{2}$ photocatalysts and their environmental applications, Catal. Surv. Asia 10, 16-28. DOI: 10.1007/s10563-006-9000-2.

49. Fujishima, A., Rao, T.N., Tryk, D.A. (2000). Titanium dioxide photocatalysis, J. Photoch. Photobio. C 1, 1-21. DOI: 10.1016/S1389-5567(00)00002-2.

50. Zhao, L., Han, M. \& Lian, J. (2008). Photocatalytic activity of $\mathrm{TiO}_{2}$ films with mixed anatase and rutile structures prepared by pulsed laser deposition, Thin Solid Films 516, 3394-3398. DOI: 10.1016/j.tsf.2007.10.102.

51. Sharfrin, E. \& Zisman, W.A. (1960). Constitutive relations in the wetting of low energy surfaces and the theory of the retraction method of preparing monolayers. J. Phys. Chem. 64, 519-524. DOI: 10.1021/j100834a002.

52. Moulder, J., Stickle, W., Sobol, P. \& Bomben, K. (1995). Handbook of X-ray Photoelectron Spectroscopy, USA: Physical Electronics Inc., ISBN 0-9648124-1-X.

53. Wang, T.M., Zheng, S.K., Hao, W.C. \& Wang, C. (2002). Studies on photocatalytic activity and transmittance spectra of $\mathrm{TiO}_{2}$ thin films prepared by r.f. magnetron sputtering method, Surf. Coat. Technol. 155, 141-145. DOI: 10.1016/S0257-8972(02)00004-X.

54. Tauc, J. (1970). Optical Properties of Solids, Amsterdam, North Holland

55. Jing, L.Q., Yuan, F.L., Hou, H.G., Xin, B.F., Cai, W.M., Fu, H.G. (2005). Relationships of surface oxygen vacancies with photoluminescence and photocatalytic performance of ZnO nanoparticles. Sci. China Ser. B Chem. 48(1), 25-30. DOI: $10.1360 / 03 y b 0191$.

56. Boulbar, E., Millon, E., Ntsoenzok, E., Hakim, B., Seiler, W., Boulmer-Leborgne, C. \& Perriere, J. (2012). UV to NIR photon conversion in $\mathrm{Nd}$-doped rutile and anatase titanium dioxide films for silicon solar cell application. Opt. Mater. 34, 1419-1425. DOI: 10.1016/j.optmat.2012.02.033. 